\title{
Психолого-педагогические технологии преодоления смыслового барьера в учебном процессе
}

\author{
Алла А. Осипова ${ }^{1 *}$, Лидия А. Дятлова², Евгения Н. Рядинская ${ }^{3}$, \\ Марина А. Лукьяненко ${ }^{4}$ \\ ' Донской государственный технический университет, г. Ростов-на-Дону, \\ Российская Федерация \\ 2 Южный федеральный университет, г. Ростов-на-Дону, Российская Федерация \\ ${ }^{3}$ Донбасская аграрная академия, г. Макеевка, Донецкая Народная Республика \\ ${ }^{4}$ Кубанский государственный университет (филиал), г. Славянск-на-Кубани, \\ Российская Федерация \\ *E-mail: alla nika2006@mail.ru
}

\begin{abstract}
Аннотация
Ввеление. В современной психолого-педагогической науке рассматриваются размичные барьеры как определенные индивидуально-психологические затруднения, которые не позволяют выйти на новый уровень решения проблемы, препятствуют выполнению определенной Аеятельности, в частности, общению с определенным ^юльми (когнитивные барьеры, познавательные барьеры, коммуникативные барьеры и т. А.). Особый виА барьеров - смысловые барьеры, интерпретируются как затруднения в смыслообразовании и смыслораскрытии. В статье преАложен новый научный поАхоА к преодолению смысловых Аиссонансов в процессе взаимодействия учителя и ученика.
\end{abstract}

Теоретическое обоснование. В учебном процессе, который в фрормате современной теории смысла рассматривается как смысловая трансляция межАу учителем и учащимся, интерпретация смысловых барьеров имеет свои уникальные особенности. В процессе смыслового взаимодействия межАу учителем и учеником возникают разные уровни смыслового принятия, при этом могут возникать смысловые барьеры как субьективный Аиссонанс, как затруднение в смыслопоисковой Аеятельности и в актуализации смыслов на уровне осознания, смысловой рефлексии. Смысловые барьеры в контексте учебного процесса могут отличаться от смысловых барьеров в иных контекстах по механизмам, фуункциям и способам преололения.

Результаты. Аифореренциация смысловых барьеров в учебном процессе ставит переА авторами статьи необходимость поиска направленных и опосредованных технологий по преололению смысловых барьеров в обучении, которые могут Аать возможность моделировать учебные ситуации с целью преодоления смысловых барьеров в реальной практике учебного процесса. Авторы проанализировали 
различные технологии смысловых инициаций, выявили их АиАактические эфофекты и развивающие ресурсы, представили экспериментальные исследования, полтвержАающие эфорективность преАложенного подхода.

Обсужаение результатов. Анализ различных педагогических технологий показал возможности их применения Аля преололения смысловых барьеров в обучении.

\section{КАючевые слова}

смысл, смыслообразование, смысловой барьер, образовательная среда, учитель, ученик, учебный процесс, педагогические технологии, технологии смыслообразования, задачи на смысл

\section{Основные положения}

- на современном этапе развития образования психолого-педагогические техно^огии преололения смысловых барьеров в обучении являются олним из наиболее актуальных направлений совершенствования процесса обучения;

- смысловые барьеры, возникающие в учебной Аеятельности, выполняют по отношению к этой Аеятельности Авоякую фуункцию: конструктивную и Аеструктивную; - регулирующее воздействие смысловых барьеров позволяет блокировать низкоэорорективные стратегии обучения и направлять поисковую активность субъектов обучения на овлаление более эороективными стратегиями;

- полученные результаты демонстрируют необхолимость развития в смысловой парадигме образования вопросов технологического обеспечения.

\section{Благодарности}

Исследование выполнено в рамках реализации Задания № 25.7450.2017/БЧ «Разработка технологий инициации смыслообразования как компонента современных коммуникативных систем с целью обеспечения информационной безопасности сети Интернет» (№ ВнГр-07/2017-01**).

\section{Для цитирования}

Осипова А.А., Дятлова Л.А., Рядинская Е.Н., Лукьяненко М. А. Психолого-педагогические технологии преодоления смыслового барьера в учебном процессе // Российский психологический журнал. 2018. Т. 15, № 2. С. 260-278. DOI: 10.21702/rpj.2018.2.11

Материалы статьи получены 26.08.2017 


\title{
Psychological and Pedagogical Technologies for Overcoming Meaning Barriers in the Learning Process
}

\author{
Alla A. Osipova ${ }^{3}$, Lidiya A. Dyatlova ${ }^{2}$, Evgeniya N. Ryadinskaya ${ }^{3}$, Marina A. Luk'yanenko ${ }^{4}$ \\ ${ }^{1}$ Don State Technical University, Rostov-on-Don, Russian Federation \\ ${ }^{2}$ Southern Federal University, Rostov-on-Don, Russian Federation \\ ${ }^{3}$ Donbass Agrarian Academy, Makeevka, Donetsk People's Republic \\ ${ }^{4}$ Kuban State University, Branch in Slavyansk-on-Kuban, Slavyansk-on-Kuban, Russian \\ Federation \\ *Corresponding author. E-mail: alla_nika2006@mail.ru
}

\begin{abstract}
Introduction. In modern psychological and educational science various barriers are considered to be certain psychological obstacles preventing an individual from reaching a new level in problem solving and obstructing the implementation of ongoing activities, in particular, communication with others (e. g., cognitive barriers, learning barriers, communication barriers). Meaning barriers - a specific type of barriers - are interpreted as obstacles in meaning-making and meaning-revealing. The paper introduces a new approach to overcoming meaning barriers in the teacher-student interaction process.
\end{abstract}

Theoretical Basis. In the learning process, which the modern theory of meaning defines as the process of transferring meanings between the teacher and the student, interpreting meaning barriers has its unique characteristics. In the teacherstudent meaning interactions, the acceptance of meanings takes place at various levels. In so doing, meaning barriers may emerge as a subjective dissonance, as an obstacle to meaning-seeking activities and to the actualization of meanings at the level of awareness and meaning reflection. Meaning barriers in the learning process may differ from those in other contexts by their mechanisms, functions, and means that could be used to overcome them.

Results. When analyzing the differentiation of meaning barriers in the learning process, the authors faced the necessity to search for both direct and indirect means of overcoming meaning barriers to learning, which could be instrumental in modeling learning situations in order to overcome meaning barriers in the actual practice of the learning process. The authors analyzed various technologies for meaning initiations, discovered their didactic effects and developing resources, and presented the experimental studies confirming the effectiveness of the suggested approach.

Discussion. The analysis of various pedagogical technologies demonstrated their potential applicability for overcoming meaning barriers to learning. 


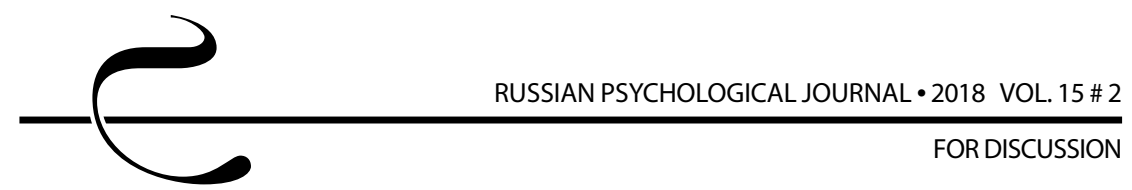

\section{Keywords}

meaning, meaning-making, meaning barrier, educational environment, teacher, student, learning process, pedagogical technologies, technologies for meaningmaking, meaning problems

\section{Highlights}

- Psychological and pedagogical technologies for overcoming meaning barriers to learning are among the most topical directions for improving the learning process in modern education.

- Arising from learning activities, meaning barriers function as both constructive and destructive factors for such activities.

- The regulatory effect of meaning barriers blocks less effective learning strategies and redirects learners' searching activities toward acquiring more effective strategies. - The obtained results suggest the importance of developing technological ensuring for the framework of meanings in education.

\section{Acknowledgments}

Supported by the project no. 25.7450 .2017 (grant 07/2017-01**) for the Development of Technologies for Meaning-Making Initiation as a Component of Modern Communication Systems for Ensuring Information Security on the Internet.

\section{For citation}

Osipova A.A., Dyatlova L. A., Ryadinskaya E. N., Luk'yanenko M. A. Psychological and Pedagogical Technologies for Overcoming Meaning Barriers in the Learning Process. Rossiiskii psikhologicheskii zhurnal - Russian Psychological Journal, 2018, V. 15, no. 2, pp. 260-278 (in Russian). DOI: 10.21702/rpj.2018.2.11

Original manuscript received 26.08.2017

\section{Введение}

Введение новых образовательных стандартов и формирование соответствующего социального запроса актуализируют для педагогического сообщества проблему поиска новых эффективных технологий в обучении $[1,2]$. Реалии современной образовательной среды порождают ряд определенных проблем учебного процесса, связанных со смысловым диссонансом между системой ценностей учителя и системой ценностей ученика $[3,4]$. В результате этого возникает противоречие, вследствие которого учеником не может быть понят учебный материал, изучен и освоен, а учителем (преподавателем) не может быть донесен определенный объем знаний согласно требованиям современных стандартов обучения; при этом проблема постигаемого учебного 
материала на уровне смыслового принятия приобретает особое значение, т. к. возникают не просто познавательные, когнитивные, эмоциональные барьеры, которые традиционно рассматриваются в контексте учебных проблем, а возникают специфические смысловые барьеры, происхождение которых детерминировано различным пониманием жизненных ценностей, жизненных отношений [5]. При этом смысловые барьеры могут возникать не только у обучаемого, но и у обучающего, а в ситуации одновременного формирования смысловых барьеров у субъектов образовательного процесса процесс трансляции и усвоения знаний становится крайне неэффективным и малопродуктивным $[6,7]$. Самостоятельное преодоление возникшего смыслового барьера субъектами обучения или снижение его выраженности с течением времени маловероятно, необходимы специальные усилия, в частности, овладение учителем специальными техниками, приемами и технологиями.

Целью данной статьи является проведение анализа дидактического ресурса психолого-педагогических технологий в преодолении смыслового барьера в обучении.

В современной науке делаются попытки разработать дидактические технологии, которые будут инициировать не просто возникновение единичных ситуативных смыслов в рамках урока или учебной ситуации, но и влиять на всю траекторию ценностно-смыслового развития. Эти технологии призваны актуализировать смысложизненные ориентации обучающихся, формировать ценности, определять жизненные приоритеты $[2,3,7,8,9,10,11,12,13$, $14,15]$. В дидактике предложено несколько типологий и классификаций таких методов и технологий по уровню их смыслоинициирующего потенциала. Однако при описании таких технологий и механизмов их реализации в практике учебного процесса зачастую не описаны те из них, которые не просто инициируют смыслообразование, но и помогают преодолеть возникшие в ходе обучения смысловые барьеры как противоречие между оценочной позицией учителя и ученика, как диссонанс смыслов обучаемого и сущности постигаемого учебного содержания, как реальное затруднение выразить свои ценности в вербальной форме, которые могут быть «раскристаллизованы» другими участниками коммуникативного взаимодействия [5]. Специфика таких технологий описана в данной статье.

\section{Теоретическое обоснование}

Смысловой барьер феноменологически может быть концептуализирован как определенное психическое состояние, возникающее либо перед началом выполнения деятельности, либо во время ее выполнения. Возникшее состояние (смысловой барьер) либо не позволяет развернуться деятельности, 


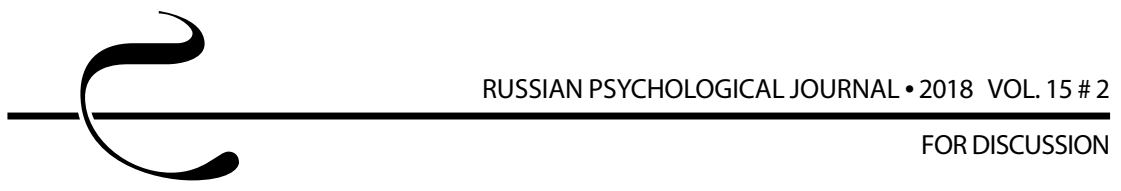

либо блокирует и дезорганизует уже начавшуюся деятельность. Подобное состояние вызывает достаточно высокий уровень нервно-психического напряжения, для снижения которого личность может использовать различного рода психологические защиты; при этом причины, которые привели к возникновению смыслового барьера (внешние или внутренние), могут быть скрыты от личности в сфере бессознательного, и чем менее зрелой (в возрастном или социальном плане) будет личность, тем менее ею могут быть осознаны истинные причины затруднений в деятельности $[16,17,18,19,20]$.

Образование является развивающей средой, в которой происходит смыслоразвитие личности, поэтому для становления индивидуальных смыслов обучаемых при освоении содержания образования необходимо создание специальных условий. По мнению Е.Г. Беляковой, «...общие условия смыслообразования при изучении предметов разных учебных циклов реализуются через индивидуализацию обучения, активизацию личностно-смыслового фактора в отборе и освоении содержания образования, привлечение гуманитарных текстов, межпредметную интеграцию на аксиологической основе. Специфические условия смыслообразования связаны с интерпретационным потенциалом текстов, выступающих в качестве содержания образования, возрастно-психологическими особенностями обучающихся, их базовыми смысловыми установками и уровнем образования» [8, с. 112-113].

Смыслообразование трактуется ею «как развитие индивидуальных смыслов участников педагогического взаимодействия - их обогащение и обретение ими многомерности через взаимодействие с личностными смыслами других субъектов педагогического взаимодействия, с педагогическими смыслами» $[8$, с. 6].

По отношению к учебной деятельности смысловые барьеры выполняют двоякую функцию: деструктивную и конструктивную. Деструктивная функция смыслового барьера заключается в том, что происходит снижение уровня самооценки, фрустрируются креативные способности, происходит снижение эффективности образовательной деятельности, формируется неудовлетворенность результатами деятельности. Конструктивная функция смыслового барьера (включающая в себя защитные, стабилизирующие, регуляторные и мобилизационные аспекты) проявляется в том, что сознание субъектов обучающей деятельности ограждается от травмирующих переживаний, вызванных внутренними и внешними конфликтами, происходит мобилизация внутренних ресурсов организма, замедляются мыслительные и волевые процессы, сдерживающие активность.

Преодоление смыслового барьера позволяет личности перейти к новому уровню развития, актуализировать все ранее скрытые потенциалы, а мобилизованные ресурсы придают активности новый вектор, что приводит 
к резкому снижению уровня тревоги, нормализации значительного количества психических процессов, появлению ряда новообразований - адекватной самооценки, умения принимать конструктивные решения и т. п. [21].

Д.А. Леонтьев указывает на то, что существует как естественное развитие смысловой динамики, так и возможность произвольного развития смысловой сферы при помощи различных смыслотехник. Возможно как развивать собственную произвольную активность субъекта, направленную на управление процессами смысловой регуляции, так и управлять смысловой динамикой другого человека. В этом случае смыслотехники будут выступать в качестве частного случая психотехники. В качестве объекта воздействия смыслотехник выступает смысловая динамика, а именно процессы смыслообразования, смыслоосознания и смыслостроительства [10]. С точки зрения Д. А. Леонтьева, именно посредством этих процессов осуществляются изменения в смысловой сфере [22].

К таким смыслотехническим изменениям можно отнести особенности волевой регуляции (произвольность управления побуждением), возможность повышения или понижения мотивации, рефлексивный анализ, особенности смыслового выбора, технику сократовского диалога и т. д. [23]. При этом можно как воздействовать на особенности отдельного поведенческого акта, так и через определенные смысловые диспозиции осуществлять воздействие на устойчивые отношения к определенным людям или вещам, формировать или трансформировать общие смысловые ориентации - мировоззрение, самоотношение, систему ценностей [5].

В психолого-педагогическом дискурсе существуют теоретическое обоснование возможностей инициации смыслообразования, практические разработки и технологии, носящие смыслообразующий характер (С.В. Гуров, С.Ю. Зильбербранд и др.) $[9,18,19,24,25,26,27]$. При всем многообразии технологий, методов и форм обучения необходимо отметить, что далеко не все из них обладают смыслоинициирующим потенциалом, необходимым для формирования или трансформации учебных установок, учебных ценностей и учебных мотивов.

В современной педагогической психологии существует раздел, связанный с изучением технологий, использование которых позволит учителю или преподавателю активизировать смыслообразующую деятельность обучаемых. Разработка технологии смысловой активизации требует учета психологических механизмов инициации смыслообразования, а также учета действия механизмов, тормозящих смыслообразование [1, 2].

Новодидактика позволяет рассмотреть психологический механизм инициации процесса смыслообразования в процессе обучения с принципиально новой позиции: «...согласно традиционной дидактике, технологии 


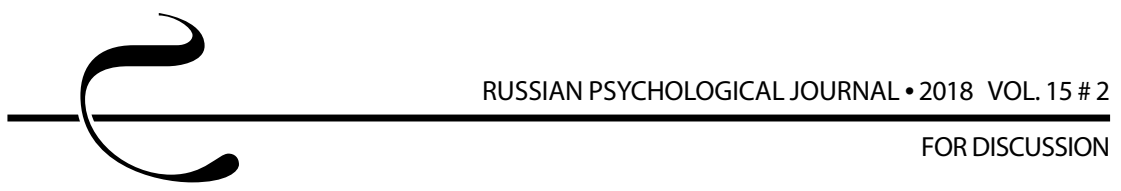

по отношению к содержанию образовательного процесса вторичны, выступают своеобразной надстройкой, механизмом его реализации. В “Новодидактике” нередки случаи обратной зависимости - содержания от технологий, когда технология в действиях педагога настолько укореняется, что подчиняет себе само содержание. Это можно видеть на примере диалога как образовательной технологии, который предписывает особое, проблемное содержание. Более того, сама технология может перейти в ранг содержания. Если согласиться, что содержание есть то, что подлежит освоению, и предположить, что при помощи того же диалога освоен какой-то фрагмент учебного материала, то при этом освоенным может оказаться и сам диалог и справедливо истолкован как содержание. Наконец, согласно Новодидактике, в обучении имеется и такая сфера, в которой образовательные технологии не "в чести". Здесь "в чести" психологическая, нравственная, дидактическая поддержка» $[2$, с. 18].

Опираясь на теорию смысловых инициаций, можно обозначить исходные предпосылки внесения смыслов в реальные методики организации учебного процесса: «технологии направленного формирования ценностно-смысловых установок в учебном процессе как педагогические технологии имеют разный смыслообразующий потенциал и разные траектории реализации в практике учебного процесса в зависимости от их уровня смысловой актуализации и смыслообразующего потенциала. Технологии субъективации содержания (наполнения его потенциально раскрываемыми смыслами), его одновременная и последующая объективация (когда содержание имеет смысл для всех), присвоение (раскристаллизация) смысла обучаемым (каждым для себя) должны быть реализованы в реальном учебном процессе лишь с учетом того, что содержание функционирует на нескольких уровнях, которые отражают логику построения учебного процесса от проектирования до реализации, от того момента, когда преподаватель начинает планировать и определять приоритеты определяемого содержания, до непосредственного раскрытия и присвоения обучающимися смысла того, что изучается» [2, с. 70].

Теоретический анализ позволил выйти на уровень эмпирического исследования дидактических технологий с точки зрения их потенциала как смыслообразующих инициаций.

\section{Результаты}

Анализ результатов эмпирических исследований по использованию технологий инициации смыслообразования в практике учебного nрочесса

В исследовании И.Е. Нестеренко была предпринята попытка анализа и оценки традиционных дидактических технологий в учебном процессе 
с точки зрения наибольшего потенциала смыслообразования, и была предложена следующая типология технологий, обладающих высоким смыслообразующим потенциалом [19]:

«- технологии, которые обеспечивают ряд аспектов самоактуализации субъектного опыта обучающихся (инициация смыслообразов посредством актуализации смысловых установок и смысловых обобщений);

- технология диалога (внешний, внутренний, множественный диалоги, межкультурный диалог);

- технологии с использованием игрового компонента (ролевые, дидактические, учебно-деловые и другие виды игр);

- проблемно-творческие технологии (создание и рефлексия проблемных ситуаций, решение задач на "смысл" ситуаций)»;

- технологии, которые связаны с самооценкой, заданиями на самопредъявление, а также с саморефлексией;

- технологии, обеспечивающие психолого-дидактическую поддержку обучаемых (задание на самоидентификацию, развитие эмпатии, развитие межличностных и внеличностных ценностей как приоритетов в формировании коллективного сознания).

Наличие смысловых барьеров препятствует процессу раскристаллизации личностных смыслов, отчуждает обучаемого от учебного материала, а непреодоленные смысловые барьеры затрудняют взаимодействие обучаемого как с педагогом, так и с учебным содержанием. Смыслообразующий эффект возникает на основе убеждающего воздействия со стороны учителя, в тот момент, когда учителем предлагается определенный содержательный материал, подлежащий усвоению. В ситуации, при которой смыслы учителя и учеников являются синхронизированными, смысловой барьер отчуждения учеников от постигаемого содержания учебного материала не возникает, т. к. учебное содержание уже имеет для учеников личностный смысл, и в инициации смыслообразования нет необходимости. Если же содержание материала, подлежащего усвоению, вызывает у ученика несогласие, то возникает смысловой барьер с разной степенью выраженности. Ученик соотносит предъявленное учебное содержание с имеющимся у него смысловым фондом, в случае совпадения смысловых центраций возникает когнитивный консонанс, и происходит инициация смыслообразования. В ситуации, при которой происходит рассогласование между элементами учебного содержания и элементами смыслового фонда, возникает когнитивный диссонанс, и смыслопорождение отсутствует. Поскольку главным источником смыслообразования обучаемых являются содержательные аспекты учебного процесса, то на характер смыслообразования, а соответственно, на риск формирования смыслового барьера, оказывают влияние 
его пространственно-временные характеристики: распределение содержания между педагогом и обучаемым, между группами обучаемых с учетом временной последовательности учебных действий.

Содержание и технологии органически взаимосвязаны - содержание «насыщает» развитие личности, ее смысловых структур, а технологии являются релизером развития. Если технология неадекватна содержанию, то она не «сработает», т. к. при этом происходит нарушение принципа изоморфной зависимости «содержание - технология». Таким образом, вопрос технологий возможного преодоления смыслового барьера в обучении переносится из дидактического плана в психологическую плоскость, т. к. содержание обучения может быть представлено на разных уровнях обучения:

- на уровне проектирования - в форме текста, знака;

- на уровне реального учебного процесса - как появление и проявление чувств, эмоций, мыслей обучаемых;

- на личностном уровне - как система смысложизненных приоритетов обучаемого, его ценностей и жизненных приоритетов.

Технологии преодоления смысловых барьеров представляют собой двусторонний стадиальный процесс овладения определенным комплексом психолого-педагогических средств, обеспечивающих определенный уровень достижения прогнозируемых результатов в конкретных условиях обучения [28]. Для решения вопроса о выборе педагогических технологий, позволяющих вооружить педагогов арсеналом методик для инициирования смыслообразования в реалиях конкретного учебного процесса, важно обратиться рассмотрению классификации психолого-педагогических учебных технологий с учетом их влияния на смыслообразование [29].

Е.С. Зорина в исследовании «Психологические основы применения смыслотехник как фактора инициации смыслообразования в учебном процессе» показала, как различные психотехники и смыслотехники могут влиять на особенности смыслообразования учащихся в реальной практике учебного процесса [10, 15]. Она предложила свою классификацию таких смыслотехник, ориентируясь на модальность перцептивного воздействия:

- смыслообразные техники (формирование ассоциативных смысловых связей, смысловые обобщения, смыслоинициирующие образы-символы);

- диалоговые техники (диалоги разных уровней смысловой насыщенности, полилоги, монологи, диалог культур и т. д.);

- игровые техники (игры-экскурсии, ролевые дидактические игры, методы конкретных ситуаций);

- техники самовыражения (самопредъявление, самооценка, рефлексия);

- смыслотехники поддержки и фасилитации (эмпатические задания, сенсорный тренинг, техники «равный - равному»); 
- смыслотехники развития креативности (арт-техники, задачи с множественными решениями, инсталляции, эвритмия).

В классах, где учебный процесс проходил с использованием данных техник с целью достижения психологического понимания, смыслового консонанса между учителем и обучающимся (по мнению Е.С. Зориной), были выявлены инициации смыслового развития по следующим направлениям:

- самооценка и саморефлексия, потребность в общественном признании $(0,356$, при $\mathrm{p} \leq 0,01)$;

- отношение к окружающим («наличие хороших друзей» $(0,223$, при $\mathrm{p} \leq 0,05)$, «чуткость» $(0,221$, при $\mathrm{p} \leq 0,05)$,«терпимость» $(0,215$, при $\mathrm{p} \leq 0,05)$, развитие эмпатических способностей $(0,274$, при $\mathrm{p} \leq 0,05)$ );

- отношение к социальным ценностям («смелость в отстаивании своего мнения» $(0,197$, при $\mathrm{p} \leq 0,05)$, социальный интеллект $(0,227$, при $\mathrm{p} \leq 0,05)$, «продуктивная жизнь» $(0,244$, при $\mathrm{p} \leq 0,05))$.

По мнению Е.С. Зориной, экспериментальное исследование по использованию смыслотехник в практике преодоления смысловых барьеров показало их эффективность, повысился уровень смыслового принятия постигаемого учебного содержания, увеличилось количество учащихся с позитивными стратегиями достижения консонанса с оценочной позицией учителя [10].

И.В. Абакумовой была предложена иерархическая классификация технологий по уровню влияния на смыслообразование - от наименьшей степени к максимальной [6]:

1. Классификация технологий, основанная на критерии «способ кодирования информации». Данную группу составляют вербальные, аудиовизуальные, мультимедийные, гипертекстовые, голографические технологии.

2. Классификация технологий по критерию «величина радиуса действия учебного процесса». На этом уровне представлены технологии, которые обеспечивают усвоение материала в малом академическом пространстве в форме урока и других видов учебных занятий (объяснительно-репродуктивных, информационно-компьютерных, эвристических, проблемных, ситуативно-игровых, диалоговых).

3. Классификация технологий на основе критерия «взаимоотношения "учитель - ученик"». В данную группу входят: субъект-объектные технологии (объяснения, лекция, воспроизводящая беседа, работа по образцам, упражнения тренировочного типа), субъект-субъектные технологии (методика Эльконина - Давыдова «Образ - моделирование - интеграция», технология проблемного предъявления и построения учебного материала, технологии опережающего построения учебного процесса, крупноблочная технология подачи учебного материала); субъект-текст-субъектная технология. 


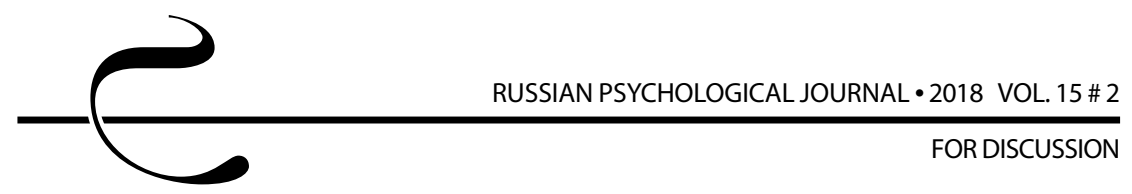

4. Классификация технологий по критерию «характер познавательной деятельности учащихся». В данную группу входят технологии репродуктивного типа (объяснение учителя с последующим воспроизведением учащимися, тренировочные упражнения), технологии проблемного типа (проблемное введение материала учителем и стимулируемая этим проблемно-поисковая деятельность учащихся; постановка проблемно-познавательных задач; диалоги, диспуты, дискуссии), технологии исследовательского типа (метод проекта, реферативная работа, экспериментирование, творческие работы обучаемых).

5. Технологии, базирующиеся на критерии «способность обеспечить личностно-смысловое развитие обучаемых». Данный тип технологий ориентирован не на «прочное усвоение знаний», не на формирование «активного мышления» и «творческой активности», а на собственно смыслообразование учащихся, сопровождающееся состояниями переживания различной степени выраженности.

Большинство авторов, которые типологизируют смыслоинициирующие технологии, отдельно выделяют диалог как технологию, которая обладает очень большим потенциалом в интересующем нас ракурсе.

В работе В. В. Суфиянова были выделены различные «уровни учебного диалога с учетом степени смысловой насыщенности:

- диалог-истолкование (ориентирован на постижение значений тех или иных понятий на рациональном уровне в результате объяснения и вопросов учителя);

- диалог-включенность (с использованием контекста, аналогичного реальным жизненным ситуациям, характерным для данной возрастной группы учащихся, от реального субъективного опыта к субъектному, жизненному миру, через раскрытие личностных смыслов данного контекста, трансформация смыслов в совместной деятельности);

- диалог-проникновение (учебная коммуникация как направленная трансляция смыслов определенных содержательных фрагментов постигаемой информации, инициация смыслообразования учащихся преподавателем);

- диалог-переживание (выведение диалога на смысловой уровень, попытка создания общего "учитель - ученик" смыслового пространства, формирование более сложных смысловых конструктов как компонентов смысложизненных ориентаций личности)» $[24$, с. 20].

Возможности использования диалога в учебном процессе как специфической технологии направленной трансляции смыслов не ограничиваются рамками частного методического приема, позволяющего решать узкопредметную задачу, а позволяют рассматривать диалог как процессуально-целостную структурно-организованную модель, способную воспроизводиться 
в различных условиях с заданным результатом. Модель диалоговой технологии может содержать следующие элементы:

- коммуникатор (субъект, задающий смысловую направленность диалога, ставящий «задачи на смысл», создающий соответствующие смысловые установки или являющийся транслятором определенных смысловых конструктов);

- код коммуникации (вид диалога: письменный или устный);

- мотивы и цели смыслообразования (то, что побуждает обучаемого в рамках диалогического общения к вербализации личностного смысла);

- содержание (как потенциальные поля «кристаллизации» смысла);

- реципиент (мотивационно-смысловые особенности субъекта).

Применение диалога в качестве технологии направленной трансляции смыслов позволяет транслятору обращаться к актуально значимому для обучаемого опыту для актуализации скрытой силы личностных смыслов, смысловых конструктов и смысловых установок [30]. Структура модели диалога как переживания, как совместно пережитого знания «через передачу опыта, может характеризоваться следующими базовыми составляющими:

- разотождествление смысловых отношений (разделение "Я" и “Мое", через актуализацию "Я");

- полимодальная смысловая презентация (составляющая, направленная на организацию одновременной представленности сознанию двух или более отношений); выявление уровня смысловой насыщенности (составляющая, инициирующая осознание факта пересечения жизненных отношений);

- структурирование (составляющая, направленная на обнаружение или установление разного рода связей между жизненными отношениями)» $[10$, с. 37-38].

\section{Обсуждение результатов}

Исследование механизмов перехода от безличностных значений к понятиям, наполненным личностными смыслами, дают возможность разработать технологии направленной и опосредованной инициации смыслообразования учащихся, преодолеть ценностно-смысловые барьеры в реальной практике учебного процесса. Определенным препятствием для интериоризации теории смыслоинициаций в реальную практику учебного процесса является существование противоречия между обязательным атрибутом управления учебным процессом со стороны учителя и самой сущностью смысла как интенциального акта сознания, который фактически не подлежит направленному управлению. Для разрешения этого противоречия нужна новая технология обучения, основанная на достижениях смысловой психологии 


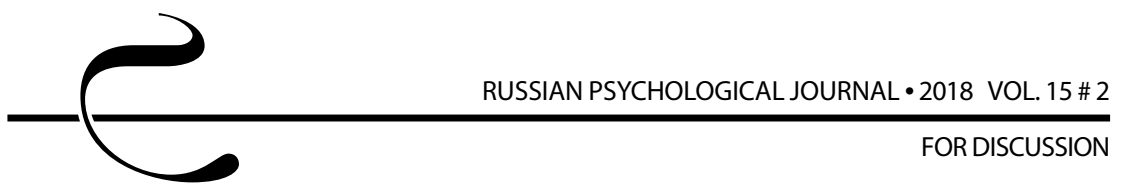

и предлагающая не просто описание механизмов функционирования смысла в практике учебного процесса как направленного познания, но и выявляющая технологии воздействия на смыслообразующий потенциал участников. Необходимо создать и привнести в практику учебного процесса методы и технологии, которые будут инициировать именно смысловое развитие обучающихся, выводить систему взаимодействия «учитель - ученик» на уровень смыслового понимания и принятия друг друга.

В современной психолого-педагогической науке предложено несколько типологий преодоления смысловых барьеров в реальной практике учебного процесса. Большинство из них экспериментально апробированы и обоснованно могут рассматриваться как технологии смыслоинициаций. Они имеют определенные сходства и различия. Практически все предложенные технологии содержательно основаны на развитии трех основных смысловых центраций (отношение к себе, к окружающим и общественным ценностям), а процессуально - на диалоговых и фасилитирующих технологиях, однако сама режиссура и практика реализации имеет свои существенные особенности: в зависимости от возраста (школьники, студенты, взрослые), от уровня сложности и пролонгированности учебной программы (ситуации переподготовки, специфика образовательных целей, продолжительность обучения, уровень когнитивной сложности постигаемого материала, доступность интерактивных методов и т. д.). При анализе диалога как базовой технологии преодоления смысловых барьеров разные авторы трактуют его результат как достижение смыслового консонанса, как сближение оценочных позиций разных участников учебного процесса, а смысловой консонанс в свою очередь помогает человеку ощутить себя понятым и эмоционально близким как одноклассникам, так и учителю, который начинает казаться тем, кто высказывает позиции, которые можно принять как личностно близкие.

\section{Заключение}

Несмотря на то, что в современной психолого-педагогической науке проанализировано достаточно большое количество дидактических технологий, которые обладают смыслоинициирующим потенциалом, технологии, которые помогают преодолеть смысловые барьеры в учебном процессе, нуждаются в отдельных исследованиях. Для решения дидактического противоречия и нужны смыслотехнологии, которые будут «работать» на его преодоление. Технологии преодоления смысловых барьеров представляют собой двусторонний стадиальный процесс овладения определенным комплексом психолого-педагогических средств, обеспечивающих определенный уровень достижения прогнозируемых результатов в конкретных условиях обучения. 
Такой подход позволяет не только расширить инструментальные возможности педагогов, но и внести существенные изменения в организацию реального учебного процесса, в переосмысление его целей, содержания и методов.

\section{Литература}

1. Абакумова И. В., Ермаков П. Н., Фоменко В. Т. Новодидактика. Книга 1. Методология и технологии обучения: в поисках развивающего ресурса. М.: КРЕДО, 2013. 162 с.

2. Абакумова И. В., Ермаков П. Н., Фоменко В. Т. Новодидактика. Книга 2. Образовательные технологии: новые ракурсы. М.: КРЕДО, 2013. 122 с.

3. Асмолов А. Г. Оптика просвещения: социокультурные перспективы. М.: Просвещение, 2012. 447 с.

4. Кагермазова Л. Ц. Формирование индивидуального стиля педагогического общения у будущих учителей: Учебно-методические рекомендации. Нальчик: Изд-во КБГУ, 2006. 45 с.

5. Ермаков П. Н., Абакумова И. В., Осипова А. А. Смысловые барьеры в обучении: дидактическое содержание и технологии преодоления: монография. М.: КРЕДО, 2016. 274 с.

6. Абакумова И. В. Смыслообразование в учебном процессе: дисс. ... д-ра психол. наук. Ростов н/Д, 2003. 440 с.

7. Абакумова И. В., Ермаков П. Н., Кагермазова Л. Ц. Технологии направленной трансляции смыслов в практике учебного процесса. М.: КРЕДО, 2016. 234 c.

8. Белякова Е. Г. Смыслообразование в педагогическом взаимодействии. Тюмень: Изд-во Тюменского государственного университета, 2008. 208 с.

9. З Зильбербранд Н. Ю. Дидактическая сущность смысловых задач // Вестник Череповецкого государственного университета. 2013. Т. 2, № 4 (52). C. 106-109.

10. Зорина Е. С. Психологические особенности смыслотехник в ситуации инициации смыслообразования в учебном процессе: дисс. ... канд. психол. наук. Ростов н/Д, 2017. 208 с.

11. Kelly G. The Psychology of Personal Constructs. N. Y.: Norton, 1955. XVIII. 1210 p.

12. Mednick S. A. The Associative Basis of the Creative Process // Psychological Review. 1962. Vol. 69, № 3. P. 220-232.

13. Abakumova I. V., Ermakov P. N., Kolesina K. Y. On analyzing the results of empirical research into the life-purpose orientations of adults of various ethnic identities and religious affiliations // Psychology in Russia: State of the Art. 2016. Vol. 9, № 1. P. 155-163. DOI: 10.11621/pir.2016.0111

14. Fedotova O. D., Ermakov P. N., Abakumova I. V., Latun V. V. The peculiarities of updating the interconnection of neuroscience and education in the dis- 
sertation discourse // EDULEARN17 Proceedings. Barcelona, Spain: IATED, 2017. P. 4728-4733. DOI: 10.21125 /edulearn.2017

15. Abakumova I. V., Zorina E. S. Sense-making techniques in educational process and their impact on the personal characteristics of students //International Journal of Cognitive Research in Science, Engineering and Education. 2017. Vol. 5, № 2. P. 41-46. DOI: 10.5937/IJCRSEE1702041A

16. Абакумова И. В., Годунов М. В., Енин А. Л., Генердукаева 3. Ш. Стратегии смыслообразования: современные представления в работах отечественных исследователей (учебное пособие). М.: КРЕДО, 2016. 36 с.

17. Годунов М. В. Ансамбль свойств личности: интерпретация и диагностика биполярных семантических шкал. Книга 1. М.: КРЕДО, 2016. 365 с.

18. Гуров С. В. Психологические особенности смыслообразования студентов: типы, стили, стратегии // Российский психологический журнал. 2012. T. 9, № 1. С. 62-66.

19. Нестеренко И. Е. Психолого-дидактические особенности формирования смысловых установок старшеклассников в учебном процессе: дисс. ... канд. психол. наук. Ростов н/Д, 2009. 198 с.

20. Werlen B. Society, Action and Space: An Alternative Human Geography. Translated by Gayna Walls / T. Brennan and B. Werlen (Eds.). London and N. Y.: Routledge, 1993. 249 p.

21. Леонтьев Д. А. Методика изучения ценностных ориентаций. М.: Смысл, 1992. $17 \mathrm{c}$.

22. Леонтьев Д. А. Психология смысла: природа, строение и динамика смысловой реальности. М.: Смысл, 2007. 511 с.

23. Агафонов А. Ю. Основы смысловой теории сознания. М.: Речь, 2003. 296 с.

24. Суфиянов В.В. Диалог как педагогическая технология в смыслообразующем учебном контексте: автореф. дисс. ... канд. пед. наук. Ростов н/Д, 2007. 24 с.

25. Brehm J. Post-decision changes in desirability of alternatives // Journal of Abnormal and Social Psychology. 1956. № 52. P. 384-389.

26. Cattell R. B. The Scientific Analysis of Personality. Harmondsworth, England: Penguin Books, 1965. 399 p.

27. Festinger L. A Theory of Cognitive Dissonance. Evanston, Illinois: Row, Peterson \& Company, 1957. 291 p.

28. Language, Meaning, and Culture: The Selected Papers of C. E. Osgood / C. E. Osgood \& O. Tzeng (Eds). N. Y.: Praeger Publishers, 1990. 428 p.

29. Белова Е. В., Лукьяненко М. А. «Задачи на смысл»: диалоговые формы и условия использования в учебном процессе // Российский психологический журнал. 2014. Т. 11, № 3. С. 33-40.

30. Бодалев А. А. Психология общения. Энциклопедический словарь / под общ. ред. А. А. Бодалева. Изд. 2-е. М.: Когито-Центр, 2015. 627 с. 


\section{References}

1. Abakumova I. V., Ermakov P. N., Fomenko V. T. Novodidaktika. Kniga 1. Metodologiia i tekhnologii obucheniia: $v$ poiskakh razvivaiushchego resursa [New-didactics. Book 1. Methodology and technologies of education: In search of a developing resource]. Moscow, KREDO Publ., 2013. 162 p.

2. Abakumova I. V., Ermakov P. N., Fomenko V. T. Novodidaktika. Kniga 2. Obrazovatel'nye tekhnologii: novye rakursy [New-didactics. Book 2. Educational technologies: New viewpoints]. Moscow, KREDO Publ., 2013. 122 p.

3. Asmolov A. G. Optika prosveshcheniya: sotsiokul'turnye perspektivy [The optics of education: Sociocultural perspectives]. Moscow, Prosveshchenie Publ., 2012. 447 p.

4. Kagermazova L. Ts. Formirovanie individual'nogo stilya pedagogicheskogo obshcheniya u budushchikh uchitelei [Forming an individual style of pedagogical communication in future teachers]. Nalchik, KBGU Publ., 2006. 45 p.

5. Ermakov P. N., Abakumova I.V., Osipova A. A. Smyslovye bar'ery vobuchenii:didakticheskoe soderzhanie i tekhnologii preodoleniya [Meaning barriers in learning: Didactic content and means of overcoming]. Moscow, KREDO Publ., 2016. 274 p.

6. Abakumova I.V. Smysloobrazovanie v uchebnom protsesse [Meaning making in the learning process]. Diss. Dr. Sci. (Psych.). Rostov-on-Don, 2003. 440 p.

7. Abakumova I. V., Kagermazova L. Ts., Ermakov P. N. Tekhnologii napravlennoi translyatsii smyslov $v$ praktike uchebnogo protsessa [Technologies of the directed transferring meanings in the learning process]. Moscow, CREDO Publ., 2016. 234 p.

8. Belyakova E. G. Smysloobrazovanie v pedagogicheskom vzaimodeistvii [Meaning-making in pedagogical interaction]. Tyumen, Tyumen State University Publ., 2008. 208 p.

9. Zil'berbrand N. Yu. Didactic essence of meaning problems. Vestnik Cherepoveckogo gosudarstvennogo universiteta-Bulletin of the Cherepovets State University, 2013, V. 2, no. 4 (52), pp. 106-109 (in Russian).

10. Zorina E. S. Psikhologicheskie osobennosti smyslotekhnik v situatsii initsiatsii smysloobrazovaniya $v$ uchebnom protsesse [Psychological characteristics of meaning techniques in a situation of meaning-making initiation in the learning process]. Diss. Cand. Sci. (Psych.). Rostov-on-Don, 2017. 208 p.

11. Kelly G. The psychology of personal constructs. N. Y., Norton, 1955. XVIII. 1210 p.

12. Mednick S. A. The associative basis of the creative process. Psychological Review, 1962, V. 69, no. 3, pp. 220-232.

13. Abakumova I. V., Ermakov P. N., Kolesina K. Y. On analyzing the results of empirical research into the life-purpose orientations of adults of various ethnic identities and religious affiliations. Psychology in Russia: State of the Art, 2016, V. 9, no. 1, pp. 155-163. DOI: 10.11621/pir.2016.0111 


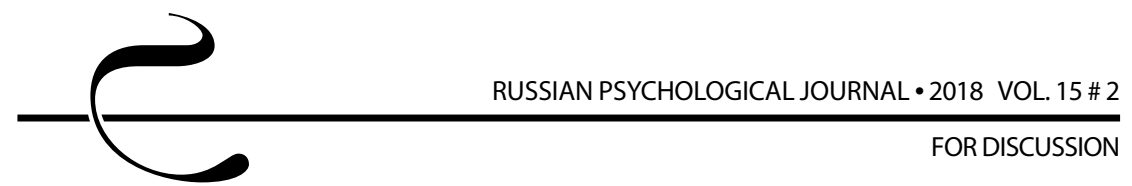

14. Fedotova O. D., Ermakov P. N., Abakumova I. V., Latun V. V. The peculiarities of updating the interconnection of neuroscience and education in the dissertation discourse. EDULEARN17 Proceedings. Barcelona, Spain, IATED, 2017, pp. 4728-4733 DOI: $10.21125 /$ edulearn.2017

15. Abakumova I.V., Zorina E. S. Sense-making techniques in educational process and their impact on the personal characteristics of students. International Journal of Cognitive Research in Science, Engineering and Education, 2017, V. 5, no. 2, pp. 41-46. DOI: 10.5937/IJCRSEE1702041A

16. Abakumova I. V., Godunov M. V., Enin A. L., Generdukaeva Z. Sh. Strategii smysloobrazovaniya: sovremennye predstavleniya v rabotakh otechestvennykh issledovatelei [Meaning-making strategies: Modern ideas in the works of domestic researchers]. Moscow, KREDO Publ., 2016. 36 p.

17. Godunov M.V.Ansambl'svoistv lichnosti:interpretatsiya idiagnostika bipolyarnykh semanticheskikh shkal [The ensemble of personal traits: Interpretation and diagnostics of bipolar semantic scales]. Moscow, KREDO Publ., 2016, V. 1. $365 \mathrm{p}$.

18. Gurov S. V. Psychological characteristics of students' meaning-making: Types, styles, and strategies. Rossiiskii psikhologicheskii zhurnal - Russian Psychological Journal, 2012, V. 9, no. 1, pp. 62-66 (in Russian).

19. Nesterenko I. E. Psikhologo-didakticheskie osobennosti formirovaniya smyslovykh ustanovok starsheklassnikov vuchebnom protsesse [Psychological and didactic characteristics of formation of senior pupils' meaning attitudes in the learning process]. Diss. Cand. Sci. (Psych.). Rostov-on-Don, 2009. 198 p.

20. Werlen B. Society, action and space: An alternative human geography. London and N. Y., Routledge, 1993. $249 \mathrm{p}$.

21. Leont'ev D. A. Metodika izucheniya tsennostnykh orientatsii [Technique for studying value orientations]. Moscow, Smysl Publ., 1992. 17 p.

22. Leont'ev D. A. Psikhologiya smysla: priroda, stroenie i dinamika smyslovoi real'nosti [Psychology of meaning: Nature, structure and dynamics of meaning reality]. Moscow, Smysl Publ., 2003. 511 p.

23. Agafonov A. Yu. Osnovy smyslovoi teorii soznaniya [Foundations of a meaning theory of consciousness]. Moscow, Rech' Publ., 2003. 296 p.

24. Sufiyanov V. V. Dialog kak pedagogicheskaya tekhnologiya $v$ smysloobrazuyushchem uchebnom kontekste [Dialogue as a pedagogical technology in a meaning-making educational context]. Autoabstract, Diss. Cand. Sci. (Pedag.). Rostov-on-Don, 2007. 24 p.

25. Brehm J. Post-decision changes in desirability of alternatives. Journal of Abnormal and Social Psychology, 1956, no. 52, pp. 384-389.

26. Cattell R. B. The scientific analysis of personality. Harmondsworth, England, Penguin Books, 1965. 399 p. 
для дискуссии

27. Festinger L. A theory of cognitive dissonance. Evanston, Illinois, Row, Peterson \& Company, 1957. 291 p.

28. Osgood C. E. \& Tzeng O. (eds.) Language, meaning, and culture: The selected papers of C. E. Osgood. N. Y., Praeger Publishers, 1990. 428 p.

29. Belova E. V., Luk'yanenko M. A. Meaning problems: Dialog forms and use conditions in the learning process. Rossiiskii psikhologicheskii zhurnal-Russian Psychological Journal, 2014, V. 11, no. 3, pp. 33-40 (in Russian).

30. Bodalev A. A. (ed.) Psikhologiya obshcheniya. Entsiklopedicheskii slovar' [Psychology of communication: Encyclopedic dictionary]. Moscow, Kogito-Tsentr Publ., 2015. 627 p. 